\title{
DESIGUALDADES DE OPORTUNIDADES E SEGREGAÇÃO RESIDENCIAL: a metropolização da questão social no Brasil
}

\author{
Luiz Cesar de Queiroz Ribeiro*
}

\begin{abstract}
O presente artigo objetiva analisar a relação entre vulnerabilidade social e as tendências à segmentação e segregação residencial em nossas grandes cidades. Tem-se como pressuposto que, em todas as sociedades capitalistas, existiram diferentes sistemas de gestão dos riscos à reprodução material e à coesão social. Nas metrópoles brasileiras, a vulnerabilidade social decorre da crise de um regime de bem-estar social dual, fundado a partir da combinação das livres forças de mercado e da mobilizacão das estruturas familiar-comunitárias, particularidades do nosso desenvolvimento capitalista. Escolhemos como indicador de vulnerabilidade social os segmentos da população de 4 a 24 anos, que correspondem a vários ciclos de socialização e de aquisição dos recursos necessários à reprodução e à integração sociais, cuja situação de vulnerabilidade se diferencia de acordo com a importância da família, da escola e (ou) do mercado na reprodução social desse grupo. Os resultados indicam que, independentemente da localização da moradia, se no centro ou na periferia das metrópoles, se nas regiões mais favorecidas ou não, o contexto social do "bairro" onde há pouco capital social na forma de relações estáveis com o mercado de trabalho aumenta os riscos de que essa população esteja em situação de vulnerabilidade. Portanto, é possível pensar num padrão de sociabilidade marcado por um isolamento social com baixo grau de exposicão aos ativos que permitem superar essa situação que, ao mesmo tempo, é marcada pela instabilidade da vida social. PALAvRAS-CHAvE: metrópoles, questão social, vulnerabilidade social, segregação residencial.
\end{abstract}

\section{INTRODUÇÃO}

A hipótese da metropolização da questão social brasileira decorre da análise da relação entre vulnerabilidade social e as tendências à segmentação e à segregação residencial em nossas grandes cidades. Para a finalidade deste trabalho, assumimos a noção de vulnerabilidade social como a situação de risco que veda ou bloqueia indivíduos, famílias ou grupos fragilizados socialmente de adquirirem os ativos necessários à reprodução objetiva e subjetiva. Tomando uma forma tangível ou intangível, os ativos a que fazemos alusão são aqueles capazes de dotar seus portadores das condições materiais e sociais que promovem a participação dos indivíduos na sociedade sob bases consideradas socialmente como legítimas. Eles são acessados em três esferas da sociedade: o mercado, o Estado e a família ou comunidade, de cuja

* Doutor em Arquitetura e Urbanismo. Professor titular da Universidade Federal do Rio de Janeiro-Instituto de Pesquisa e Planejamento Urbano e Regional- IPPUR/UFRJ. Bolsista de produtividade em pesquisa do CNPq.

Av. Pedro Calmon, 550, sala 537- Prédio da Reitoria Cidade Universitária - Ilha do Fundão. Cep: 21941-901 Rio de Janeiro, RJ - Brasil. cesar@ippur.ufrj.br combinação faz surgir, em cada sociedade, regimes de bem-estar social (Esping, 1995), que cumprem o papel de gestão dos riscos de crise da reprodução das relações sociais. Segundo esse autor, podemos identificar, na história do capitalismo, três regimes de bem-estar social, segundo a dimensão da matriz sociocultural que prevalece em cada sociedade: a) a gestão da força de trabalho como mercadoria; b) a produção da integração social; e c) a igualdade como utopia des-mercantilizadora.

O primeiro regime, considerado como residual anglo-saxão, tem como fundamento a autossuficiência individual - workfare-, fazendo com que o seu dilema atual seja o de como converter as massas trabalhadoras expulsas do mercado de trabalho industrial em um novo proletariado de serviços. No regime chamado de corporativo, surgido nos países da Europa, a crise do estado de bem-estar social se coloca como a impossibilidade de satisfazer as necessidades inerentes às promessas de integração social. A questão social subjacente à crise desse regime de bem-estar constrói-se em torno do dilema de como devolver ao Estado sua capacidade de agente integrador da sociedade. Por 
último, o regime universalista - ou escandinavo foi centrado na busca da igualdade como finalidade do estado de bem-estar social e, como consequência, a questão social é formulada em torno do debate a respeito dos graus possíveis de manutenção dessa igualdade.

Em resumo, em todas as sociedades capitalistas, tornou-se necessária a existência de um sistema de gestão dos riscos da reprodução e da descoesão social, convivendo com o mercado, seja ele fundado em sistema público de redistribuição ou nas relações de reciprocidade inerentes à organização familiar-comunitária.

A partir desses pressupostos e tomando como referência as particularidades históricas do desenvolvimento do capitalismo no Brasil, assumimos que a problemática da vulnerabilidade presente nas grandes metrópoles brasileiras deve ser entendida como decorrente da crise do regime de bem-estar social dual, forjado ao longo da fase do desenvolvimento das relações capitalistas conhecida na literatura como substituição das importações, e fundado na combinação das livres forças de mercado e na mobilização das estruturas familiar-comunitárias. Com efeito, na condição de capitalismo periférico, ocorreu um processo inacabado de mercantilização da força de trabalho, ao mesmo tempo em que as forças desencadeadas pelo capital des-ruralizaram o país, criando uma vasta massa urbana marginal constituída por segmentos de trabalhadores assalariados de maneira precária, por conta-própria, trabalhadores sem remuneração e desempregados, ou mesmo alijados das relações mercantis. Essa particularidade do nosso capitalismo fez com que a reprodução social nunca tenha se colocado como custo da acumulação do capital. Consequentemente, a reprodução social esteve historicamente fundada na combinação entre mercado-família e comunidade. Como consequência, foi transferida às famílias e às comunidades a função de gestão dos riscos da reprodução social.

Em resumo, a via do desenvolvimento do capitalismo no Brasil, apesar da modernização cultural, da industrialização e da urbanização, constitui um regime de bem-estar social que, na tipologia proposta por Esping-Andersen (1995), podemos identi- ficar como próximo à variante "familístico-mercantil” (Esping, 1995), embora, para alguns segmentos profissionalizados e sindicalizados, tenha se instituído um corporativo welfare state. É importante assinalar que a eficácia desse modelofundou-se, antes de tudo, na manutenção de um regime político caracterizado fortemente por governos autoritários e ditatoriais, que permitiram a instauração de um processo controlado de incorporação das massas urbanas ao sistema político e aos benefícios do crescimento econômico acelerado. Santos (1994), ao cunhar a expressão de "cidadania regulada", ${ }^{1}$ ofereceu uma chave teórica para a compreensão desse processo. Ao mesmo tempo, no plano dos valores organizadores do sentido coletivamente compartilhado das interações sociais, o nosso regime "familísticomercantil" de bem-estar social fundou-se também na matriz sociocultural que legitimou a ordem social, ao mesmo tempo competitiva e estamental, como bem demonstrou Florestan Fernandes.

A fisionomia, a vida social, a organização social do território, enfim todos os aspectos da realidade urbana das nossas grandes cidades vão expressar as várias facetas desse regime de gestão de risco. Como já mencionou em vários dos seus trabalhos Francisco de Oliveira, ao caráter inacabado da mercadoria força de trabalho corresponde o caráter inacabado do habitat urbano brasileiro.

Essas formulações fundam a orientação deste trabalho. Adotamos como hipótese, na investigação empírica aqui empreendida, que a vulnerabilidade social crescente em nossas metrópoles decorre dos efeitos da fragilização do nosso regime "familístico-mercantil" de bem-estar social e a sua crescente incapacidade de assegurar a reprodução social, a integração e a legitimidade da ordem social. Tal fragilização decorre da combinação de três processos de transformação em curso da sociedade brasileira, cujo epicentro está nas metrópoles: a crescente segmentação do mercado ur-

${ }^{1}$ Por "cidadania regulada” entende-se uma forma parcial e incompleta de cidadania que privilegia alguns segmentos ocupacionais em detrimento do conjunto das classes subalternas, na medida em que exclui do padrão de proteção social as demais categorias de trabalhadores urbanos (não-regulamentadas pelo Estado Novo), os informais, os autônomos, os rurais, os domésticos e os desempregados e indigentes. Ver Santos (1994). 
bano de trabalho, a fragilização da família como unidade de socialização, e do bairro como comunidade territorializada de reprodução social. Esse último processo relaciona-se estreitamente com as transformações em curso da nossa ordem urbana, tanto no plano da sua morfologia quanto da ordem moral, em razão dos mecanismos de segmentação e segregação urbana.

O objetivo deste trabalho é gerar evidências empíricas sobre essas hipóteses, tomando como universo de pesquisa as 15 principais metrópoles da rede urbana brasileira e usando como base as informações do censo 2000. Na próxima seção, apresentamos os indicadores e o modelo de análise construído tendo em vista tal objetivo. $\mathrm{Na}$ subsequente, exploramos os resultados obtidos na aplicação desse modelo. Buscamos, ao final, propor alguns pontos de reflexão.

\section{VULNERABILIDADE SOCIALE SEGREGAÇÃO RESIDENCIAL: indicadores e modelo de análise}

As 15 metrópoles escolhidas são os aglomerados urbanos que exercem funções metropolitanas na rede urbana brasileira. ${ }^{2} \mathrm{~A}$ nossa hipótese é de que, nesse conjunto, configurou-se de maneira mais forte o nosso regime de bemestar social "familísiticomercantil”, responsável pelo padrão urbano de reproduçãosocial correspondenteao nosso modelo de desenvolvimento capitalista.

${ }^{2}$ Essas 15 metrópoles, segundo estudo realizado pelo Observatório das Metrópoles (OBSERVATÓRIO, 2009), são: Belém, Belo Horizonte, Brasília, Campinas, Curitiba, Florianópolis, Fortaleza, Goiânia, Manaus, Porto Alegre, Recife, Rio de Janeiro, Salvador, São Paulo e Vitória.
Partimos da construção de um modelo de análise sintetizado na figura abaixo.

Escolhemos como indicador de vulnerabilidade social os segmentos da população de 4 a 24 anos que correspondem a vários ciclos de socialização e de aquisição dos recursos necessários à reprodução e à integração sociais. Podemos falar em situações de vulnerabilidade social em função da importância diferenciada da família, da escola e do mercado na reprodução social desse grupo. Assim escolhemos os seguintes indicadores:

- Crianças de 4 até 5 anos de idade residentes em famílias sem nenhuma pessoa com 20 anos ou mais desocupada (todos os adultos fora de casa) e com renda familiar per capita de 1/2 SM, que estão fora da escola ou da creche, configurando a situação de desamparo materno-infantil.

- Crianças de 7 até 14 anos de idade, com 2 anos ou mais de atraso escolar ou que estão fora da escola ou creche, configurando a situação atraso escolar.

- Mães de 15 até 19 anos, solteiras, que não trabalham, não estudam e não procuram emprego, configurando a situação risco de bloqueio da sua socialização frente à escola e ao trabalho.

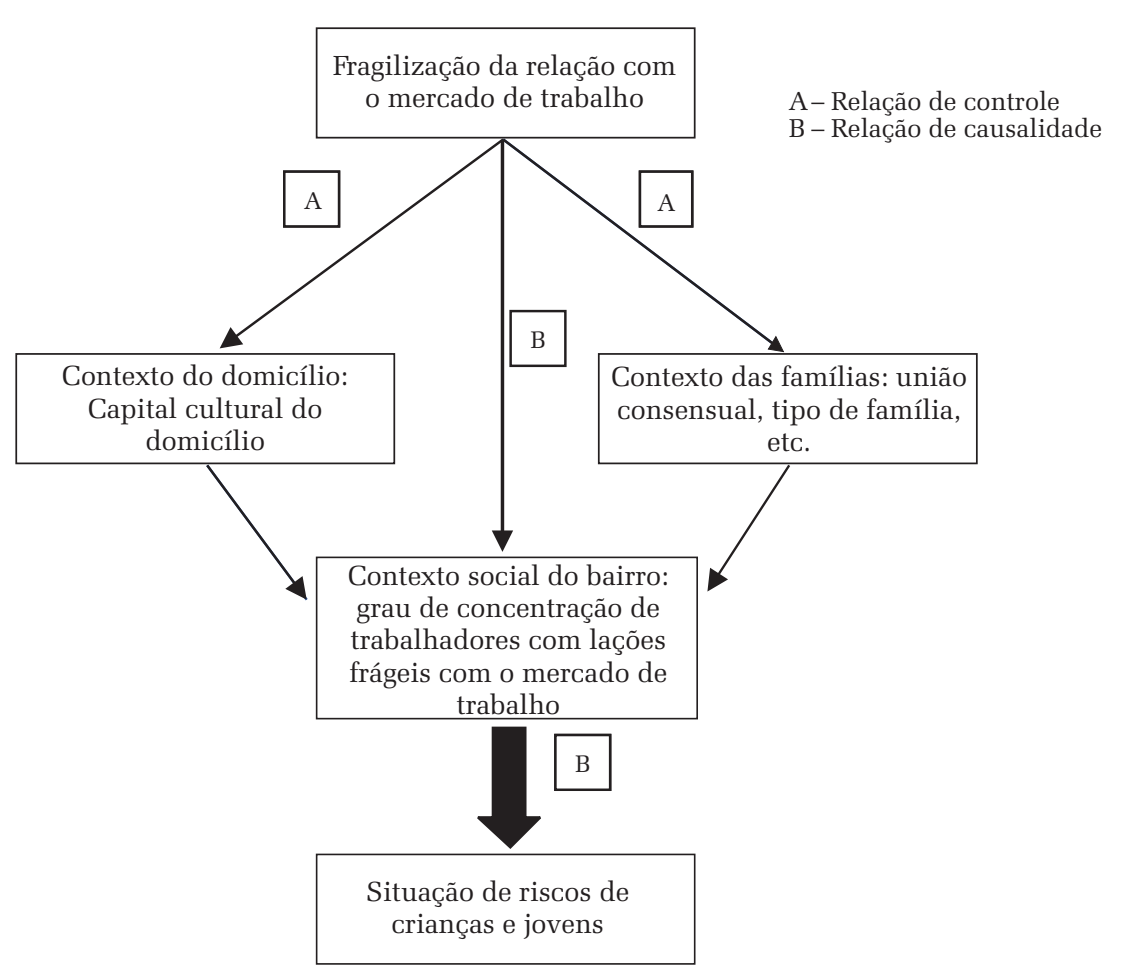


- Mães de 15 até 19 anos, solteiras, que trabalham ou estudam ou procuram emprego, configurando uma situação de risco distinto em relação à anterior, na medida em que, mesmo com dificuldades, estão inseridas em uma das duas instituições socializadoras.

- Jovens, responsáveis, exceto mães de 15 até 24 anos de idade, que não trabalham, não estudam e não procuram emprego, configurando uma situação de quem assume o papel de constituição da família, mas está alijado das outras duas instituições: a escola e o trabalho.

- Jovens, responsáveis, de 15 até 24 anos de idade, exceto mães, que não trabalham, não estudam, mas procuram emprego, configurando uma situação de vulnerabilidade frente ao mercado de trabalho.

- Jovens, não-responsáveis, exceto mães, de 15 até 24 anos de idade que não trabalham, não estudam, mas procuram emprego, configurando a condição do desocupado.

- Jovens, não-responsáveis, exceto mães de 15 até 24 anos de idade, que não trabalham, não estudam e não procuram emprego. Trata-se, nesse caso, da situação extrema de vulnerabilidade em razão de esse jovem não estar assumindo nenhum dos papéis socialmente exigidos frente às três instituições: família, escola e trabalho.

Ao designarmos como vulnerabilidade as situações descritas anteriormente, estamos chamando a atenção para as "heranças" recebidas por essas crianças e jovens, traduzidas pela não-aquisição de recursos materiais e imateriais necessários à futura integração na sociedade. Tais recursos são adquiridos nos processos de socialização e aprendizagem que ocorrem nos universos do domicílio, da família, do bairro e do trabalho. Assim, procuramos identificar as relações de causalidade entre as situações de vulnerabilidade acima definidas e os seguintes contextos sociais.

\section{Contexto do domicílio}

\section{Capital Escolar}

Utilizamos a média de anos de estudos dos maiores de 20 anos de idade e denominamos esse indicador de "clima escolar do domicílio" como proxy do capital cultural existente, ou seja, como recurso no âmbito domiciliar à disposição das crianças e jovens. Para fins da análise, ele foi estratificado nas seguintes faixas:

- População da $\mathrm{AED}^{3}$ residente em domicílio, com clima educativo de até 5 anos de estudo.

- População da AED residente em domicílio, com clima educativo de 5 até 9 anos de estudo.

- População da AED residente em domicílio, com clima educativo de 9 até12 anos de estudo.

- População da AED residente em domicílio, com clima educativo de mais de 12 anos de estudo.

\section{Contexto da família}

\section{Arranjos familiares e tipos de união dos respon- sáveis pela família}

- União incompleta, considerada como a monoparentalidade. Vários estudos brasileiros têm apontado mudanças no universo familiar. São mudanças em razão dos efeitos da transição demográfica em curso nos últimos 20 anos, associadas às transformações econômicas e sociais desse período. A primeira tendência é a diminuição do tamanho das famílias, em razão da queda da fecundidade. A segunda tendência é a diminuição da proporção de domicílios multigeracionais e o aumento correlativo das famílias monoparentais e unifamiliares (Halsenbalg, 2003, p.61-62). Outra mudança importante é o aumento das famílias instáveis. Esses dois arranjos familiares - famílias monoparentais e instáveis - são as que nos interessam pelos seus impactos na socialização das crianças e jovens,

${ }^{3}$ Área de Expansão da Amostra Domiciliar do Censo 2000 
na medida em que a ausência do cônjuge - na maioria dos casos, o homem - dificulta o exercício do da função socializadora das crianças e dos adolescentes. Por outro lado, esse arranjo diminui a quantidade de capital cultural, o que, certamente, diminui as chances de as crianças e adolescentes aproveitarem eventuais oportunidades geradas pelo Estado e pelo mercado.

- Uniões instáveis. Consideramos as uniões instáveis como uniões consentidas, não formalizadas no âmbito do registro civil ou do religioso. A fragilização encontra-se no fato de a instabilidade expressar-se, na maioria das vezes, nas frequentes mudanças de parceiro.

- Uniões estáveis. Consideramos união estável a situação em que a família se apresenta como completa e estável, pela sua constituição através da união formalizada legal ou religiosamente. ${ }^{4}$

\section{Capital econômico das famílias}

Ausência de recursos econômicos na família, medido pelo logaritmo da renda per capita familiar.

\section{Contexto social do bairro}

\section{Capital social}

Essa variável foi operacionalizada por meio da identificação do contexto social do lugar de mo- radia da população em situação de vulnerabilidade. Para tanto, buscamos construir um indicador da composição das AEDs através do percentual das pessoas que moram em domicílios cujo responsável exerce ocupações consideradas estáveis, protegidas e bem remuneradas ${ }^{5}$ sobre o total da população residente. Esse indicador pressupõe que quanto maior a diversidade da composição social do lugar de moradia, pela presença de pessoas que ocupam posições estáveis e protegidas da hierarquia sócio-ocupacional, maior acumulação do capital social no plano comunitário, resultante de: (i) acesso a recursos, (ii) maior eficiência normativa das condutas, (iii) maiores chances de ações coletivas e, por último, (iv) maiores chances de as crianças e jovens serem expostos a modelos exitosos de papel social. Para operacionalizar esse indicador, classificamos as AEDs em três grupos, a partir da concentração de pessoas que moram em domicílios cujo responsável exercia uma das ocupações definidas como estável e protegida, usandose, para tanto, a técnica da classificação hierárquica ascendente. Então, o indicador do capital social passa a ser utilizado como uma variável categórica com três posições: baixa, para AEDs com baixa concentração de alto status e, nessa mesma lógica, depreendendo-se os níveis médio e superior. A Tabela 1 mostra a distribuição do contingente da população de 4 a 24 anos em situação de vulnerabilidade.

Os dados sugerem a existência de forte concentração da população em condições de

Tabela 1 - Distribuição da vulnerabilidade nas 15 metrópoles selecionadas segundo a locação dos domicílios nos tipos socio-espaciais

\begin{tabular}{l|c|c|c}
\hline $\begin{array}{l}\text { Tipo de Status ocupacional } \\
\text { das áreas intrametropolitanas }\end{array}$ & $\begin{array}{c}\text { População em situação de } \\
\text { vulnerabilidade }\end{array}$ & $\begin{array}{c}\text { População com idade } \\
\text { entre 4 e 24 anos }\end{array}$ & $\begin{array}{c}\text { (\%) de população em } \\
\text { situação de } \\
\text { vulnerabilidade }\end{array}$ \\
\hline Baixo & 3.356 .236 & 15.716 .754 & 21,4 \\
\hline Médio & 626.254 & 3.461 .625 & 18,1 \\
\hline Superior & 345.259 & 3.054 .548 & 11,3 \\
\hline Total Global & 4.327 .749 & 22.232 .927 & 19,5 \\
\hline
\end{tabular}

Fonte: Censo Demográfico 2000, FIBGE. Tabulação Observatório das Metrópoles

${ }^{4}$ Seria necessária uma discussão sobre essas categorias de uniões estáveis e instáveis e suas relações com a com a natureza da formalização da conjugalidade. Não há, porém, espaço para tanto no quadro deste artigo. Remetemos os leitores aos trabalhos de Kaztman e Filgueiras ${ }^{5}$ No Anexo, apresentamos a lista das ocupações assim (2003) e Kaztman (2005). 
Tabela 2 - Percentual de risco, segundo a localização dos domicílios na estrutura metropolitana e nos tipos socio-espaciais nas 15 metrópoles selecionadas $(\%)$

\begin{tabular}{l|c|c|c|c}
\hline \multirow{2}{*}{ Integração no Aglomerado } & \multicolumn{3}{|c}{ Tipo socio-espacial das áreas intrametropolitanas } \\
\cline { 2 - 5 } & Baixo & Médio & Superior & Total \\
\hline Pólo & 34,20 & 10,50 & 6,60 & 51,30 \\
\hline Muito Alta & 23,60 & 2,70 & 0,90 & 27,20 \\
\hline Alta & 10,90 & 0,80 & 0,30 & 12,00 \\
\hline Média & 6,80 & 0,40 & - & -20 \\
\hline Baixa & 1,70 & - & - & 1,70 \\
\hline Muito Baixa & 0,30 & 14,50 & 8,00 & 0,30 \\
\hline Total & 77,60 & - & 100,00 \\
\hline
\end{tabular}

Fonte: Censo Demográfico 2000, FIBGE, Tabulação Observatório das Metrópoles.

vulnerabilidade nos espaços onde também se concentra a população com relações instáveis e desprotegida no mercado de trabalho. Procuramos também analisar a relação entre vulnerabilidade social e a localização da população segundo a posição do município de residência na estrutura interna das metrópoles. Na Tabela 2, podemos observar como se distribuem os percentuais de vulnerabilidade, quando olhamos, ao mesmo tempo, o nível de integração no aglomerado metropolitano e no tipo socioespacial.

Escolhemos também analisar a relação entre a vulnerabilidade social na escala das grandes regiões do país, em função das conhecidas desigualdades sociais existentes nos planos intra e intermetropolitano, fortemente correlacionadas com as conhecidas desigualdades regionais do país.

\section{OPERACIONALIZAÇÃO DO MODELOERE- SULTADOS}

A primeira exploração dos dados indicou a existência de forte associação entre o contexto social dos "bairros" (AEDs) e a situação total de vulnerabilidade. Há uma forte correlação entre a concentração de pessoas por AEDs em domicílios cujos responsáveis exercem ocupações que, segundo nosso critério, apresentam relações fortes com o mercado de trabalho, que denominamos de alto status (estáveis, protegidas e bem remuneradas); e a vulnerabilidade total associada à AED. Dessa maneira, podemos observar que, nas AEDs onde é elevado o percentual de domicílios com alto status ocupacional, a vulnerabilidade tende a diminuir. O coeficiente de correlação entre eles é de aproximadamente-0,72. A ideia de que a experiência de uma boa inserção no mercado de trabalho produz um reforço na socialização das crianças e jovens parece ganhar fôlego quando observamos essa forte correlação inversa entre o alto status e o risco.

Considerando o modelo de análise descrito anteriormente e os indicadores apresentados, foi construído um modelo estatístico para capturar as relações de causalidades entre os indicadores dos vários contextos sociais e a situação de vulnerabilidade nos 15 principais aglomerados urbanos mencionados anteriormente. Apresentamos, a seguir, o modelo e os resultados para o conjunto da situação de vulnerabilidade total (modelo 1), de atraso escolar (modelo 2) e de jovens que não trabalham, não estudam e nem procuram emprego (modelo 3).

Face à característica hierárquica dos dados (crianças e jovens que moram em determinadas áreas), a abordagem adequada para a investigação dos efeitos do local de moradia sobre o risco de estar em situação de vulnerabilidade é a modelagem da regressão multinível. ${ }^{6}$ Mais especificamente, a análise dos dados foi realizada por meio de

${ }^{6}$ A utilização dessa técnica impõe a explicitação de algumas consideracões que se relacionam com os procedimentos adotados Frequentemente, trabalhos baseados em modelos de regressão logística apresentam os resultados obtidos em função da exponenciação do coeficiente de cada um dos regressores. A exponenciação do coeficiente associado a uma variável representa a razão de chance (odds ratio). Quando o evento representado pela variável dependente é raro, a razão de chance quantifica diretamente 
modelos de regressão logística de dois níveis:

- Nível I- (a) característica individual, segundo a qual escolhemos a cor da população considerada em situação de vulnerabilidade; (b) capital educativo do domicílio, e (iii) grau de estabilidade da família, considerando os arranjos familiares e o tipo de conjugalidade.

- Nível II - (a) capital social do bairro, traduzido na composição social nos tipos de AEDs construídos, segundo o grau de concentração de pessoas em domicílios cujos responsáveis exercem ocupações estáveis, como definido anteriormente, indicador que comporta 3 posições: (baixo, médio e alto); (b) localização das AEDs nos municípios que conformam as grandes regiões do país (Norte-Nordeste, Sul, Centro-Oeste e Sudeste); e, (c) e a localização das AEDs na estrutura interna das metrópoles, expressa pelo grau de integração sociodemográfica com a dinâmica metropolitana. ${ }^{7}$
O Quadro 1 apresenta a hierarquia dos indicadores utilizados em função do modelo teórico de análise apresentado anteriormente.

A distribuição das características da distribuição das três situações de vulnerabilidade, segundo os indicadores e níveis de análise escolhidos, é apresentada na Tabela 3.

Apresentamos, a seguir, os resultados dos 3 modelos estimados, segundo os três tipos de vulnerabilidade aqui considerados. Ressaltamos ainda que as variáveis contínuas foram centradas em torno de suas respectivas médias e que a análise fez uso do peso amostral.

Adotamos como estratégia estimar os riscos para os três tipos de vulnerabilidade em três variantes. Na primeira, utilizamos as os indicadores nas escalas do indivíduo e dos contextos domiciliares, familiares e das AEDs; na segunda, incluímos os contextos macrorregionais; e, por último, na terceira, riscos relativos à localização das AEDs

Quadro 1 - Variáveis utilizadas

\begin{tabular}{|c|c|c|}
\hline Variáveis & Tipo & Descrição \\
\hline \multicolumn{3}{|l|}{ Variáveis dependentes } \\
\hline Vulnerabilidade total & Dicotômica & $(1=\operatorname{sim} / 0=$ c.c $)$ \\
\hline Vulnerabilidade tipo 1 & Dicotômica & $\begin{array}{l}\text { Indica crianças entre } 4 \text { e } 14 \text { anos fora da creche ou escola ou com atraso. } \\
(1=\operatorname{sim} / 0=\text { c.c })\end{array}$ \\
\hline Vulnerabilidade tipo 2 & Dicotômica & $\begin{array}{l}\text { Indica jovens, exceto risco_c } 1 \text {, de } 15 \text { até } 24 \text { anos, que não trabalha, não } \\
\text { estuda e nem procura emprego. }(1=\operatorname{sim} / 0=\text { c.c })\end{array}$ \\
\hline \multicolumn{3}{|l|}{ Variáveis explicativas } \\
\hline \multicolumn{3}{|l|}{ Nível 1} \\
\hline Monoparental & Dicotômica & \\
\hline União Consensual & Dicotômica & \\
\hline Clima escolar até 5 anos & Dicotômica & \\
\hline Clima escolar de 5 a 9 anos & Dicotômica & \\
\hline Clima escolar de 9 a 12 anos & Dicotômica & \\
\hline Preto & Dicotômica & \\
\hline Pardo & Dicotômica & \\
\hline Renda familiar & & Logaritmo da Renda per capita do domicílio \\
\hline \multicolumn{3}{|l|}{ Nível 2} \\
\hline Tipo sócio espacial baixo & Dicotômica & \\
\hline Tipo sócio-espacial médio & Dicotômica & \\
\hline Região Centro-Oeste & Dicotômica & \\
\hline Região Sul & Dicotômica & \\
\hline Região Norte/Nordeste & Dicotômica & \\
\hline Integração Pólo/Muito Alta & Dicotômica & \\
\hline
\end{tabular}

o risco associado à mudança de categorias da variável explicativa. Infelizmente, este não é o caso da situação de vulnerabilidade das metrópoles analisadas. Por esse motivo, apresentamos nossos resultados em função do Risco Relativo (RR), que estima a razão entre as probabilidades de estar em situação de vulnerabilidade para as categorias de resposta da variável explicativa.

${ }^{7}$ Cabe ressaltar que testamos se os coeficientes variavam entre as unidades de nível 2 e verificamos que somente o intercepto variava entre as unidades desse nível. Por isso, fixamos os coeficientes associados às demais variáveis. 
Tabela 3 - Características dos indicadores

\begin{tabular}{l|c|c|c|c|c|c}
\hline \multirow{2}{*}{ Indicadores } & \multicolumn{2}{|c|}{ Vulnerabilidade Total } & \multicolumn{2}{c}{ Vulnerabilidade Tipo 1 } & \multicolumn{2}{c}{ Vulnerabilidade Tipo 2 } \\
\cline { 2 - 7 } & Média & Dp & Média & Dp & Média & Dp \\
\hline Monoparental & 0,290 & 0,454 & 0,298 & 0,457 & 0,226 & 0,418 \\
\hline União Consensual & 0,318 & 0,466 & 0,318 & 0,466 & 0,375 & 0,484 \\
\hline Clima escolar até 5 anos & 0,550 & 0,498 & 0,633 & 0,482 & 0,494 & 0,500 \\
\hline Clima escolar de 5 a 9 anos & 0,302 & 0,459 & 0,268 & 0,443 & 0,316 & 0,465 \\
\hline Clima escolar de 9 a 12 anos & 0,116 & 0,320 & 0,077 & 0,266 & 0,147 & 0,355 \\
\hline Preto & 0,090 & 0,286 & 0,099 & 0,299 & 0,075 & 0,264 \\
\hline Pardo & 0,453 & 0,498 & 0,506 & 0,500 & 0,418 & 0,493 \\
\hline Renda familiar & 1,735 & 4,335 & 1,426 & 4,074 & 2,025 & 4,891 \\
\hline Tipo sócio espacial baixo & 0,776 & 0,417 & 0,804 & 0,397 & 0,771 & 0,420 \\
\hline Tipo sócio-espacial médio & 0,145 & 0,352 & 0,130 & 0,336 & 0,143 & 0,350 \\
\hline Região Centro-Oeste & 0,258 & 0,437 & 0,322 & 0,467 & 0,232 & 0,422 \\
\hline Região Sul & 0,108 & 0,311 & 0,106 & 0,308 & 0,113 & 0,317 \\
\hline Região Norte/Nordeste & 0,059 & 0,236 & 0,063 & 0,242 & 0,060 & 0,238 \\
\hline Integração Pólo/Muito Alta & 0,513 & 0,500 & 0,501 & 0,500 & 0,506 & 0,500 \\
\hline
\end{tabular}

Fonte: Censo Demográfico 2000.

nos municípios segundo o grau de integração metropolitana. A Tabela 4 apresenta os riscos relativos nessas três variantes da análise para situação de vulnerabilidade total. A parte inferior da tabela apresenta a variância associada a cada modelo e a compara com a variância do modelo incondicional.

Para a melhor compreensão dos resultados expressos nessa Tabela, é importante considerar que Risco Relativo (RR) maior que 1 significa que o indicador está associado ao aumento do risco

Tabela 4 - Modelo para o Risco Relativo (RR) de estar em situação de vulnerabilidade total

\begin{tabular}{|c|c|c|c|}
\hline & Variante 1 & Variante 2 & Variante 3 \\
\hline \multicolumn{4}{|l|}{ Nível 1} \\
\hline Monoparental & $1.29 * * *$ & $1.29 * * *$ & $1.29 * * *$ \\
\hline União Consensual & $1.30 * * *$ & $1.30 * * *$ & $1.30 * * *$ \\
\hline Clima escolar até 5 anos & $2.33^{* * *}$ & $2.33^{* * *}$ & $2.33^{* * *}$ \\
\hline Clima escolar de 5 a 9 anos & $1.72^{* * *}$ & $1.72^{* * *}$ & $1.72 * * *$ \\
\hline Clima escolar de 9 a 12 anos & $1.48^{* * *}$ & $1.48^{* * *}$ & $1.48^{* * *}$ \\
\hline Preto & $1.25 * * *$ & $1.25^{* * *}$ & $1.25^{* * *}$ \\
\hline Pardo & $1.12^{* * *}$ & $1.11^{* * *}$ & $1.12^{* * *}$ \\
\hline Renda familiar & $0.85 * * *$ & $0.85^{* * *}$ & $0.85 * * *$ \\
\hline \multicolumn{4}{|l|}{ Nível 2} \\
\hline Tipo socioespacial baixo & $1.29 * * *$ & $1.28 * * *$ & $1.30 * * *$ \\
\hline Tipo socioespacial médio & $1.12^{* * *}$ & $1.12^{* * *}$ & $1.12^{* * *}$ \\
\hline Região Centro- Oeste & & $0.96^{*}$ & \\
\hline Região Sul & & 1.01 & \\
\hline Região Norte- Nordeste & & $1.18^{* * *}$ & \\
\hline Integração P olo - Muito alta & & & $1.01 *$ \\
\hline \multicolumn{4}{|l|}{ Variância } \\
\hline Incondicional & $0.204^{* * *}$ & $0.204^{* * *}$ & $0.204^{* * *}$ \\
\hline Modelo & $0.041^{* * *}$ & $0.034^{* * *}$ & $0.041^{* * *}$ \\
\hline
\end{tabular}

$+\mathrm{p} \leq .10 ;{ }^{*} \mathrm{p} \leq 0.05 ;{ }^{*} \mathrm{p} \leq 0.01 ;{ }^{* *} \mathrm{p} \leq 0.001$ 
do desfecho representado pela variável dependente, nesse caso, estar em situação de vulnerabilidade total. Por outro lado, Risco Relativo (RR) menor do que a unidade representa diminuição do risco proteção-com relação ao desfecho desfavorável.

Na variante 1, o resultado indica que, mesmo controlado pelos indicadores nas escalas do indivíduo, do domicílio e da família, o contexto social do "bairro" (AEDs) aumenta os riscos de vulnerabilidade para a população de 0 a 24 anos, respectivamente, em $29 \%$ quando a criança e o jovem mora em espaços com alta concentração de pessoas em domicílios com frágeis relações com o mercado de trabalho (tipo baixo) e em $12 \%$ quando há uma mistura de situações (tipo médio). É importante frisar que o fato de esses riscos já serem controlados pelas demais variáveis incluídas no modelo indica a existência de mecanismos na escala da sociabilidade secundária (relações de vizinhança) na constituição dos riscos. Em outras palavras, podemos dizer que os resultados obtidos indicam haver relações entre a vulnerabilidade social e os mecanismos de segregação residencial, apesar da enorme importância dos contextos sociais domiciliares e familiares.

Com efeito, o risco de vulnerabilidade total para crianças e jovens cuja família é monoparental ou com uma união consensual é, respectivamente, $29 \%$ e $30 \%$ maior do que para jovens cujas famílias têm um tipo de conjugalidade religiosa ou civil. Com relação ao clima escolar do domicílio, os riscos estimados para até cinco anos, de cinco a nove anos e de nove a doze anos de escolaridade são, respectivamente $\mathrm{RR}=2,33 ; \mathrm{RR}=1,72 \mathrm{e} \mathrm{RR}$ $=1,48$, o que indica grande risco associado a contexto social. Isso quer dizer que, em relação às crianças e jovens que vivem em clima escolar domiciliar de até doze anos, os riscos das que são socializadas em domicílios com clima escolar até cinco anos é $123 \%$ maior; de cinco a nove anos, $72 \%$, e de nove a doze anos, $48 \%$ maiores, respectivamente. Para pardos e pretos, foram estimadas, respectivamente, $R R$. $=1,12$ e RR $=1,25$, o que indica risco de vulnerabilidade $12 \%$ e $25 \%$ maior para jovens pardos e pretos em comparação com jo- vens brancos. O aumento do logaritmo da renda per capita em uma unidade está associado a risco $15 \%$ menor.

Considerando todos esses controles introduzidos no nível da análise, o fato de encontrarmos valores expressivos de risco associados ao contexto social do "bairro" destaca a importância da combinação das relações entre a fragilização dos universos domiciliares e familiares e os mecanismos de segregação residencial. Refletiremos sobre tais mecanismos nas conclusões deste artigo. Essa conclusão é tanto mais relevante se considerarmos os resultados obtidos nas variantes 1 e 2 , que dizem respeito a mecanismos macroestruturais relacionados às desigualdades nas escalas metropolitana e regional. Os resultados da estimação na variante 2 indicam, por exemplo, que, dentre as regiões brasileiras, os moradores do Norte-Nordeste têm risco de vulnerabilidade total $18 \%$ maior do que os jovens moradores da região Sudeste, valor expressivo, mas inferior ao obtido para o indicador morar em bairros com alta concentração de pessoas com frágil relação no mercado de trabalho. Por outro lado, os resultados não indicam alterações relevantes em relação à variante 1 , com relação às estimativas pontuais dos indicadores do nível 1, bem como aquelas relativas ao tipo socioespacial das AEDs. Na variante três, observamos que a posição das AEDs na estrutura interna das metrópole segundo o grau de integração praticamente não aumenta ou diminui o risco de vulnerabilidade. Esse resultado alimenta a discussão apresentada em vários trabalhos sobre a manifestação dos fenômenos da segregação residencial e seus efeitos nas cidades latino-americanas, que deixam de se expressar fortemente no âmbito intermunicipal da estrutura metropolitana, como era no passado, quando vigorava o modelo centro-periferia. Em outros termos, os resultados da segregação residencial aumentam os riscos de vulnerabilidade total na escala intraurbana, atravessando os níveis metropolitanos e regionais. Os resultados obtidos nesta investigação parecem indicar que, independentemente da localização da moradia, no centro ou na periferia das metrópoles, e nas regiões mais favorecidas ou mais ri- 
cas, o contexto social do "bairro" onde há pouco capital social na forma de relações estáveis com o mercado de trabalho aumenta os riscos de vulnerabilidade para a população de 0 a 24 anos. Podemos supor que esse contexto está associado a um padrão de sociabilidade com baixo grau de interação com os ativos que circulam no mainstream da sociedade - o que pode significar a situação de isolamento social - e, ao mesmo tempo, marcado pela instabilidade da vida social.

\section{CONCLUSÕES}

Este trabalho se propôs a gerar evidências empíricas sobre a importância do contexto social do bairro na da geração de situação de vulnerabilidade social de crianças e jovens em vários ciclos da sua trajetória da integração à sociedade, uma vez que eles são marcados pelas relações que mantêm com três instituições sociais: a família, a escola e o trabalho. A nossa intenção foi a de, com esse exercício de modelagem, constituir referências que nos ajudem na reflexão sobre a hipótese central da qual partimos, qual seja, a tendência à metropolização da questão social como resultado da crise do regime de bem-estar social constituído na sociedade brasileira no ciclo anterior da nossa expansão capitalista, tipificado como familístico-mercantil. Trabalhamos com essa hipótese considerando que, se verdadeira, ela propiciaria uma chave promissora para se compreenderem as várias manifestações da crise social presentes nas metrópoles brasileiras, sendo uma delas o fato de as taxas de homicídios serem duas vezes maiores nas metrópoles do que no conjunto do país, atingindo, de maneira mais contundente, os jovens de 14 a 24 anos. Mas a hipótese da metropolização da questão social fundamenta-se, também, na suposição da importância das particularidades de certos contextos sociais constituídos pelos processos de segregação residencial, marcados por tendências ao isolamento e à instabilidade da vida social, nos quais essas crianças e jovens são socializadas.
Os resultados empíricos obtidos nesta investigação, se não podem ser tomados como demonstração dessa hipótese, autorizam-nos a continuar empreendendo esforços analíticos e empíricos nessa direção. Como já disse R. Merton (2002, p.175), trata-se reduzir a probabilidade de outras hipóteses serem adequadas a responder a pergunta subjacente a este trabalho: por que, no exame de várias manifestações da questão social - a pobreza, o desemprego juvenil, a criminalidade, a evasão e o atraso escolar, etc. -, encontramos um mapa social que indica fortes tendências à sua concentração em determinados territórios da metrópole?

Mas, se temos hoje boas evidências na literatura sobre a relação de causalidade entre o contexto social do bairro e uma série de fenômenos que se manifestam no plano dos indivíduos, dos domicílios e dos grupos sociais, encontramos pouca certeza sobre os seus mecanismos. Segundo Small e Newman (2001) e Small (2004), existiriam efeitos de vizinhança traduzidos em dois mecanismos: os referentes à socialização e os instrumentais. Os primeiros têm a ver com a existência, no meio social do bairro, de: (i) modelos de papéis sociais; (ii) eficiência normativa; e (iii) presença de subculturas marginais. E o encerramento socioterritorial das pessoas que vivem longos períodos de desemprego, ou subemprego e, consequentemente, de pobreza, certamente não expõe as crianças a situações em que o modelo de papel social bem sucedido através do trabalho possa servir de exemplo e incentivo à escolarização. Podemos, mesmo, esperar o contrário, ou seja, a tendência à formação de uma subcultura pautada por outros princípios éticos e morais que não incentivem o esforço via educação e trabalho. Além disso, ocorre uma baixa da eficiência normativa nas interações sociais. Já os mecanismos instrumentais são os relativos às condições sociais e materiais do bairro, que limitam ou bloqueiem a ação individual, como, por exemplo, o livre trânsito das pessoas (distância, violência, etc.). Outros autores, como Bourdieu (1993) e Wacquant (2001), por sua vez, fundados na matriz teórica, têm apontado "efeitos do lugar" expressos por 
mecanismos socioespaciais por meio dos quais se realiza a reprodução da dominação social. Cada bairro se constitui pela distribuição do volume e composição das várias formas de capital (econômico, social, cultural, simbólico) possuídas pelos grupos sociais. A segregação urbana e seus efeitos na vulnerabilidade de grupos sociais decorrem das desigualdades estruturais da sociedade.

(Recebido para publicação em julho de 2010) (Aceito em agosto de 2010)
SMALL, M.; NEWMAN, K. Urban poverty after the truly disadvantaged: the rediscovery of the family, the neighborhood, and culture. Annual Review of Sociology. California, Palo Alto, v. 27, 2001.

WACQUANT, L. Os condenados da cidade. Rio de Janeiro: Revan/Observatório, 2001.

\section{REFERÊNCIAS}

BOURDIEU, P. Efeitos do lugar. In: BOURDIEU, P. (Org.). A miséria do mundo. Rio de Janeiro: Vozes, 1997.

CEPAL. Segregación residencial y desigualdades sociales en montevideo Montevideo: 1999. (Documento preparado pela Oficina de CEPAL)

COLEMAN, J. S. Social capital in the creation of human capital. American Journal of Sociology, Chicago, v.94, p.S95-S120, 1988.

ESPING, A. O futuro do Welfare State na nona ordem mundial. Lua Nova: revista de Cultura e Política, São Paulo, n.35. 1995

HALSENBALG, C. A distribuição dos recursos familiares. In: $\quad$; VALLE SILVA et al (Org.). Origens e Destinos. Desigualdades sociais ao longo da vida. Rio de Janeiro: Tobook/IUPERJ/ FAPERJ. 2003

Discriminação e desigualdades raciais no Brasil. Rio de Janeiro: Graal, 1979.

KATZMAN, R. Aislamiento social de los pobres urbanos: reflexiones sobre la naturaleza, determinantes y consecuencias. Buenos Aires, SIEMPRO/UNESCO. 2001.

; FILGUEIRA, F. Panorama de la infancia y la familia en Uruguay. Programa de Investigación sobre Integración, Pobreza y Exclusión Social (IPES) de la Facultad de Ciencias Sociales y Comunicación Universidad Católica del Uruguay. Montevideo:Universidad Católica del Uruguay/IPES, 2003

MERTON, R. Teoria y estructura sociales. México: Fondo de Cultura Econômica, 2002

MOURA, R. et al. O metropolitano no urbano brasileiro: identificacão e fronteiras. In: RIBEIRO, L.C.Q.; SANTOS JÚNIOR, O. As metrópoles e a questão social brasileira. Rio de Janeiro: Revan/Observatório das Metrópoles, 2007.

OBSERVATÓRIO das Metrópoles. Hierarquização e identificação dos espaços urbanos. Coleção Conjuntura Urbana. Letra Capital/Observatório das Metrópoles, Rio de Janeiro, 2009.

SANTOS, Wanderley Guilherme dos. Cidadania e justiça: a política social na ordem brasileira. 3.ed. Rio de Janeiro: Campinas, 1994.

. Razões da desordem. Rio de Janeiro: Rocco, 1993.

SMAMALL, S. Vila Victoria. The transformation of social capital in a Boston Barrio. Chicago: The University Chicago Press, 2004. 


\begin{abstract}
ANEXO I
Lista de descritores de ocupações segundo a Classificação Brasileira de Ocupações de agosto de 2001. Apresentamos aqui nosso recorte feito a partir do subgrupo principal da ocupação, quer dizer, o segundo nível de desagregação da CBO.
\end{abstract}

\title{
Quadro descrição do subgrupo principal
}

Membros Superiores e Dirigentes do Poder Público

Dirigentes de Empresas e Organizações (exceto de interesse público)

Gerentes

Profissionais Policientíficos

Profissionais das Ciências Exatas, Físicas e da Engenharia

Profissionais das Ciências Biológicas, da Saúde e Afins

Profissionais do Ensino (com formação de nível superior)

Profissionais das Ciências Jurídicas

Profissionais das Ciências Sociais e Humanas

Comunicadores, Artistas e Religiosos

Técnicos Polivalentes

Técnicos de Nível Médio das Ciências Físicas, Químicas, Engenharia e Afins

Técnicos de Nível Médio das Ciências Biológicas, Bioquímicas, da Saúde e Afins

Professores Leigos e de Nível Médio

Técnicos de Nível Médio em Serviços de Transportes

Técnicos de Nível Médio nas Ciências Administrativas

Técnicos em Nível Médio dos Serviços Culturais, das Comunicações e dos Desportos

Outros Técnicos de Nível Médio 


\section{INEQUALITIES OF OPPORTUNITIES AND RESIDENTIAL SEGREGATION: the metropolization of the social issue in Brazil}

\section{Luiz Cesar de Queiroz Ribeiro}

The present article aims to analyze the relationship between social vulnerability and tendencies in the residential segregation and segmentation in our large cities. It is considered that, in all capitalist societies, there were different systems of risk management for material production and social cohesion. In Brazilian cities, the social vulnerability stems from the crisis of a dual system of social welfare, funded from a combination of free market forces and the mobilization of family-community structures, peculiarities of our capitalist development. We chose as an indicator of social vulnerability the segments of the population aged from 4 to 24 years, corresponding to different cycles of socialization and acquisition of resources necessary to social integration and reproduction, whose vulnerability is differentiated according to the importance of family, school and (or) market in the social reproduction of that group. Results indicate that, irrespective of place of residence, if in the center or the periphery of cities, if in the most privileged regions or not, the social context of "neighborhood" where there is little social capital in the form of stable relations with the labor market increases the risks that this population be in a situation of vulnerability. Therefore, it is possible to think of a pattern of sociability marked by social isolation with low exposure to assets that allow people to overcome this situation that, at the same time, is marked by the instability of social life.

KEYwORDS: large cities, social issue, social vulnerability, residential segregation.

\section{INÉGALITÉS D’OPPORTUNITÉS ET SÉGRÉGATION RÉSIDENTIELLE: la métropolisation de la question sociale au Brésil}

\section{Luiz Cesar de Queiroz Ribeiro}

L'objectif de cet article est d'analyser le lien qui existe entre la vulnérabilité sociale et les tendances à la segmentation et à la ségrégation résidentielle dans nos grandes villes. On part du présupposé qu'il y a toujours eu différents systèmes de gestion des risques pour la reproduction matérielle et la cohésion sociale dans toutes les sociétés capitalistes. Dans les métropoles brésiliennes, la vulnérabilité sociale découle de la crise d'un régime de bien-être social duel, basé sur la combinaison des forces livres du marché et de la mobilisation des structures familialescommunautaires, particularités de notre développement capitaliste. Nous avons choisi comme indicateur de vulnérabilité sociale, les segments de population de 4 à 24 ans qui correspondent à divers cycles de socialisation et d'acquisition des ressources nécessaires à la reproduction et à l'intégration sociales, dont la condition de vulnérabilité change en fonction de l'importance de la famille, de l'école et (ou) du marché dans la reproduction sociale de ce groupe. Les résultats indiquent que, indépendamment de leur localisation, c'est-à-dire que les résidences soient au centre ou dans les banlieues des grandes villes, qu'elles se situent dans des régions plus riches ou non, le contexte social du "quartier" où il y a peu de capital social en termes de relations stables avec le marché du travail, les risques sont plus grands de voir la population en situation de vulnérabilité. Il est donc possible de concevoir un modèle de sociabilité marqué par un isolement social ayant un faible degré d'exposition aux actifs qui permettraient de surmonter cette situation touchée, en même temps, par l'instabilité de la vie sociale.

MотS-CLÉs: métropoles, questions sociales, vulnérabilité sociale, ségrégation résidentielle.

Luiz Cesar de Queiroz Ribeiro - Doutor em Arquitetura e Urbanismo pela Universidade de São Paulo. Professor titular da Universidade Federal do Rio de Janeiro-Instituto de Pesquisa e Planejamento Urbano e Regional- IPPUR/UFRJ. Bolsista de produtividade em pesquisa do CNPq. Coordena o Observatório das Metrópoles e é Co-editor da revista Cadernos Metrópoles. Desenvolve estudos sobre os temas da metropolização, dinâmicas intrametropolitanas, dimensão sócio-espacial das exclusão/ integração nas metrópoles, governança urbana, cidadania gestão metropolitana. Entre as suas publicações mais recentes estão a coletânea A Cidade Contra a Escola? (Rio de Janeiro, Letra Capital, 2008), que organizou com Ruben Kaztman, e artigos e capítulos de livros como Efeito Metrópole e Acesso às Oportunidades Educacionais (EURE, Santiago, 2009) em colaboração com M. C. Kosliuski; Metrópoles e Sociabilidades: os impactos das transformações sócio territoriais das grandes cidades na coesão dos países da America Latina (Cadernos Metrópoles, São Paulo, 2008), em colaboração com Ruben Kaztman; Contruire la Cittadinanzza nella metropoli brasiliana (Cittá Del Mondo, Roma, 2009). 